Check for updates

Cite this: Chem. Commun., 2019 55, 3053

Received 4th December 2018, Accepted 25th January 2019

DOI: $10.1039 / \mathrm{c} 8 \mathrm{cc} 09655 d$

rsc.li/chemcomm

\section{A cobalt arylphosphonate MOF - superior stability, sorption and magnetism $\dagger$}

\author{
Yunus Zorlu, (D) a Doğan Erbahar, ${ }^{b}$ Ahmet Çetinkaya, ${ }^{c}$ Aysun Bulut, ${ }^{\text {ad }}$ Turan S. Erkal, \\ A. Ozgur Yazaydin, (D) Jens Beckmann (D) *f and Gündoğ Yücesan (D)*g
}

\begin{abstract}
We report a novel metal-organic framework (MOF) based on a cobalt arylphosphonate, namely, $\left[\mathrm{Co}_{2}\left(\mathrm{H}_{4}-\mathrm{MTPPA}\right)\right] \cdot 3 \mathrm{NMP} \cdot \mathrm{H}_{2} \mathrm{O}\left(1 \cdot 3 \mathrm{NMP} \cdot \mathrm{H}_{2} \mathrm{O}\right)$, which was prepared solvothermically from the tetrahedral linker tetraphenylmethane tetrakis-4-phosphonic acid ( $\mathrm{H}_{8}$-MTPPA) and $\mathrm{CoSO}_{4} \cdot 7 \mathrm{H}_{2} \mathrm{O}$ in $\mathrm{N}$-methyl-2-pyrrolidone (NMP). Compound 1 has the highest porosity (BET surface area of $1034 \mathrm{~m}^{2} \mathrm{~g}^{-1}$ ) ever reported for a MOF based on an aryl phosphonic acid linker. The indigo blue crystals of $1.3 \mathrm{NMP} \cdot \mathrm{H}_{2} \mathrm{O}$ are composed of edge-shared eightmembered $\mathrm{Co}_{2} \mathrm{P}_{2} \mathrm{O}_{4}$ rings, and are thermally very stable up to $500{ }^{\circ} \mathrm{C}$.
\end{abstract}

The discovery of metal-organic frameworks (MOFs) was a great advance in the field of porous solids. ${ }^{1}$ MOFs create ordered pore sites with tailor-made surface areas that can perform specific tasks such as sorption, catalysis, small molecule storage, proton conduction, greenhouse gas sequestration etc. ${ }^{2}$ MOFs allow post-synthetic modifications to further optimize the function of the pore sites after the initial synthesis. ${ }^{3}$ One of the drawbacks of common carboxylate-based MOFs is the poor thermal stability and sensitivity towards hydrolysis that somewhat hampers their commercial application and their use in industry. ${ }^{4,5}$ These drawbacks may be overcome by using phosphonate-based MOFs, which are chemically and thermally more robust due to the higher number of bonds between the

\footnotetext{
${ }^{a}$ Department of Chemistry, Gebze Technical University, Gebze, 41400 Kocaeli, Turkey

${ }^{b}$ Dogus University, Fac. of Engineering, Dept. of Mechanical Eng. Acibadem, Kadikoy, 34722, Istanbul, Turkey

${ }^{c}$ Department of Bioengineering, Yildiz Technical University, Esenler, Istanbul, Turkey

${ }^{d}$ School of Pharmacy, Altinbas University, Bakirkoy, Istanbul, Turkey

${ }^{e}$ Department of Chemical Engineering, University College London, London WC1E 7JE, UK

${ }^{f}$ Institut für Anorganische Chemie und Kristallographie, Universität Bremen, Leobener Straße, 28359 Bremen, Germany.E-mail: j.beckmann@uni-bremen.de ${ }^{g}$ Lebensmittelchemie und Toxikologie, Technische Universität Berlin, Berlin, Germany.E-mail: yuecesan@tu-berlin.de

$\dagger$ Electronic supplementary information (ESI) available. CCDC 1569569. For ESI and crystallographic data in CIF or other electronic format see DOI: 10.1039/ c8cc09655d
}

linkers and the inorganic domains. ${ }^{6-8}$ Phosphonates have a higher affinity for metal ions compared to the majority of the other metal binding Lewis bases. ${ }^{9,10}$ The linearly expanding 1,4-phenyldiphosphonic acid and 4,4'-biphenyldiphosphonic acids are the most widely used arylphosphonate linkers to produce metal organophosphonate compounds. ${ }^{11-15}$ Unlike their corresponding carboxylate derivatives ${ }^{16}$ the linear arylphosphonate linkers usually produce lamellar and pillared-layered networks. The close packing of hydrophobic linear organic components has led to the formation of two-dimensional $\mathrm{M}-\mathrm{O}-\mathrm{P}-\mathrm{O}-\mathrm{M}$ condensations, which are connected by the linear organic linkers to form the pillared-layered structures.

One approach to eliminate the formation of metal oxide layers and pillared-layered networks is the use of the trigonal or tetrahedral expanding ligands where organophosphonate units are well separated and three-dimensional geometry of the organic linker core is not suitable for the formation of the dense pillars. This hypothesis worked with the open-armed tritopic trigonal planar ligands that produced the hexagonal, honeycomb structured void channels connecting the trimeric one-dimensional inorganic building units $^{7}$ and this approach formed one of the most porous metal organophosphonate frameworks with surface areas up to $647 \mathrm{~m}^{2} \mathrm{~g}^{-1} \cdot{ }^{17,18}$ In a similar way, Shimizu, Zon and our group have reported novel arylphosphonate linkers expanding in tetrahedral geometry, which created the $\mathrm{Cu}-\mathrm{P}-\mathrm{O}$ cluster nodes and connected these cluster nodes to form porous $\mathrm{Cu}$-MOFs with BET surface areas of up to $794 \mathrm{~m}^{2} \mathrm{~g}^{-1} \cdot{ }^{19-21}$

Herein, we report the single crystal structure of the first porous cobalt complex $\left[\mathrm{Co}_{2}\left(\mathrm{H}_{4}-\mathrm{MTPPA}\right)\right] \cdot 3 \mathrm{NMP} \cdot \mathrm{H}_{2} \mathrm{O}\left(\mathbf{1} \cdot 3 \mathrm{NMP} \cdot \mathrm{H}_{2} \mathrm{O}\right)$ synthesized with the tetraphenylmethane tetrakis-4-phosphonic acid $\left(\mathrm{H}_{8}\right.$-MTPPA) ligand (Scheme 1$)$. The thermogravimetric analysis (TGA) indicates that $\mathbf{1} \cdot 3 \mathrm{NMP} \cdot \mathrm{H}_{2} \mathrm{O}$ has extraordinary stability at high temperatures.

The crystallization is a difficult task to achieve in metal organophosphonate chemistry as the transition metal ion affinity for phosphonate is extremely high compared to carboxylate functional groups. ${ }^{9,10}$ Metal-organophosphonate structures are often 

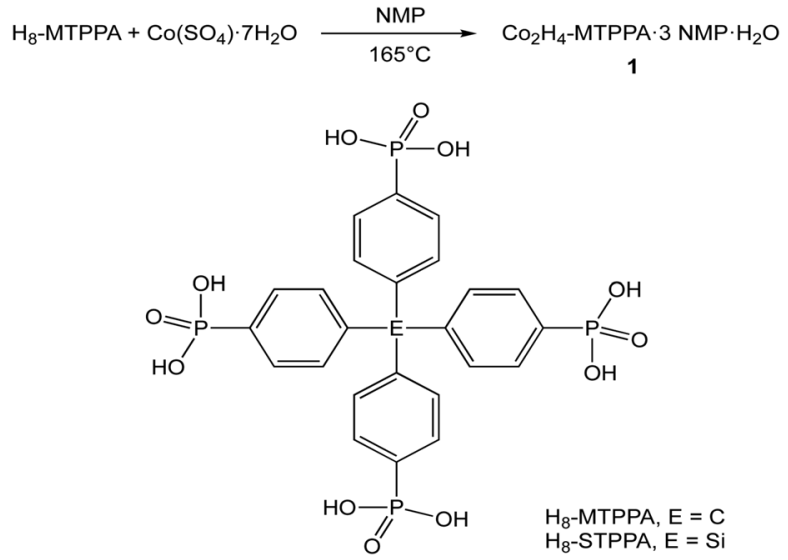

Scheme 1 Synthesis of 1.

reported using powder diffraction or recently electron diffraction methods. Stock recently reported beautiful tetraphosphonateMOFs using the planar porphyrine core using these methods, where the surface areas were up to $700 \mathrm{~m}^{2} \mathrm{~g}^{-1} \cdot{ }^{22-24}$ In order to obtain the single crystals of metal organophosphonates, we adopted a high throughput method using temperature and $\mathrm{pH}$ as the variables to optimize the crystallization conditions. ${ }^{25}$ As a result of this approach, 1.3NMP $\cdot \mathrm{H}_{2} \mathrm{O}$ was obtained as indigo blue single crystals by the solvothermal synthesis of $\mathrm{CoSO}_{4} \cdot 7 \mathrm{H}_{2} \mathrm{O}$ with $\mathrm{H}_{8}$-MTPPA in NMP as a solvent at $165^{\circ} \mathrm{C}$. Although porous cobalt organophosphonate solids are very rare in the literature, ${ }^{23}$ cobalt is an interesting element with respect to its spectroscopic and magnetic properties.

The crystal structure of $1 \cdot 3 \mathrm{NMP} \cdot \mathrm{H}_{2} \mathrm{O}$ revealed the threedimensional porous framework, which is composed of a metaloxide chain of edge-shared eight-membered $\mathrm{Co}_{2} \mathrm{P}_{2} \mathrm{O}_{4}$ rings (Fig. 1). These one-dimensional chains were connected by $\mathrm{H}_{4}$-MTPPA $^{4-}$ linkers to form the void channels via the tetrahedral $\mathrm{Co}(\mathrm{II})$ in the chain structure. The tetrahedral structure of $\mathrm{H}_{8}$-MTPPA and mono deprotonated phosphonate arms dictated the formation of tetrahedral $\mathrm{Co}$ (II) centers in 1.3NMP. $\mathrm{H}_{2} \mathrm{O}$. The whole network of 1.3NMP. $\mathrm{H}_{2} \mathrm{O}$ is composed of tetrahedral $\mathrm{R}^{-\mathrm{PO}_{3}}{ }^{2-}$, tetrahedral C atoms in MTPPA and tetrahedral $\mathrm{Co}(\mathrm{II})$, which is reminiscent of the known zeolites. As seen in Fig. 1a and c, the one-dimensional chain pattern in $\mathbf{1}$ (Fig. 1a-c) was also observed in previously reported $\mathrm{Zn}_{2} \mathrm{H}_{4}$-MTPPA and $\mathrm{Zn}_{2} \mathrm{H}_{4}$-STPPA $\left(\mathrm{H}_{8}\right.$-STPPA $=$ tetraphenylsilane tetrakis-4-phosphonic acid, Scheme 1) structures, which also produced large BET surface areas. As can be seen in Fig. 1, the previously reported Zn-MOFs with $\mathrm{H}_{8}$-STPPA and $\mathrm{H}_{8}$-MTPPA linkers indicated that the conformational changes in the edge-sharing eight-membered rings in the chain structure result in significant changes in the calculated BET surface areas. Recently, $\mathrm{ZrH}_{4}$-STPPA was reported, which also exhibited a similar one-dimensional chain structure composed of edge-shared eight-membered rings with octahedral $\mathrm{Zr}$ centers. ${ }^{26}$ The additional connectivity of the octahedral geometry increased the linker/metal ratio creating a dense three-dimensional network of $\mathrm{ZrH}_{4}$-STPPA. ${ }^{26}$

The BET surface area of $\mathbf{1}$ was derived from its simulated $\mathrm{N}_{2}$ adsorption isotherm at $77 \mathrm{~K}$ obtained by grand canonical
Monte Carlo simulations (ESI $\dagger$ ). Such calculations have been widely used for characterizing the surface area of MOF materials. ${ }^{27,28}$ The calculated BET surface area for $1,1034 \mathrm{~m}^{2} \mathrm{~g}^{-1}$, is $107 \mathrm{~m}^{2} \mathrm{~g}^{-1}$ higher than that reported for its $\mathrm{Zn}$ analogue, $\mathrm{Zn}_{2} \mathrm{H}_{4}-\mathrm{MTPPA}$, which was $927 \mathrm{~m}^{2} \mathrm{~g}^{-1} \cdot{ }^{19}$ However, it is significantly higher compared to the isostructural zinc compound $\mathrm{Zn}_{2} \mathrm{H}_{4}$-STPPA $\left(565 \mathrm{~m}^{2} \mathrm{~g}^{-1}\right)$. The same chain pattern was also observed in structurally rigid naphthalene arylphosphonate linkers with square pyramidal and octahedral metal atoms producing microporous frameworks. ${ }^{29}$ The stability of such edge shared $\mathrm{Zn}_{2} \mathrm{P}_{2} \mathrm{O}_{4}$ chains is significant as robust inorganic building units for future metal organophosphonate compounds, which could hypothetically produce isoreticularly expanding void channels with tetratopic, tritopic and ditopic ligands with expanding tether lengths. As seen in the thermogravimetric analysis graphic (see ESI $\dagger$ ), the compound is an unusually stable MOF as organic components from MTPPA start decomposing at $c a .525{ }^{\circ} \mathrm{C}$, and $27 \%$ (calculated 29.5\%) of total weight loss of MTPPA continues until $700{ }^{\circ} \mathrm{C}$. The initial $\mathrm{ca} .20 \%$ (calculated $27 \%$ ) weight loss corresponds to the solvent molecules (ESI $\dagger$ ). A recent article about ultra stable $\mathrm{ZrH}_{4}$-STPPA also shows a similar STPPA decomposition pattern but $\mathbf{1}$ is approximately $100{ }^{\circ} \mathrm{C}$ more stable than the previously reported zirconium compound, which was not porous. ${ }^{26}$ The magnetism in MOFs is an active research area. ${ }^{30-33}$ We investigated the magnetic properties of 1 via $a b$ initio calculations (ESI $\dagger$ ). Spin-polarized density functional theory analysis is performed on the structure that is revealed from XRD data and it is observed that the electronic structure tends to converge towards a state where a net spin of 3 per Co atom is established (Fig. 1d). While the charge density of this net spin has been observed to concentrate mainly around Co atoms it is not totally localized and extends throughout the structure along the $b$ axis of the crystal which may point to a ferromagnetic interaction between Co atoms as well as the magnetic anisotropy in the crystal.

In conclusion, we report an extremely stable and rare metalorganic framework (MOF) based on cobalt arylphosphonates. The calculated surface area of $1034 \mathrm{~m}^{2} \mathrm{~g}^{-1}$ indicates that 1 has the largest surface area synthesized with a tetrahedral arylphosphonic acid. The extreme stability (up to $500{ }^{\circ} \mathrm{C}$ ) at high temperatures is certainly a great advantage for potential industrial applications. Metal organophosphonates already have a myriad of applications, such as the catalysis of butane to maleic anhydride, imaging, bone remodelling, identifying micro calcifications, proton conductivity and osteoporosis treatment etc. ${ }^{34-40}$ Moreover, organophosphonates are thought to be involved in many biochemical pathways. ${ }^{41,42}$ The porous metal arylphosphonate compounds are rare but the recent efforts using the novel arylphosphonate linkers have been gradually contributing to the library of porous metal organophosphonates.

The previously reported $\mathrm{Zn}_{2} \mathrm{H}_{4}$-MTPPA, $\mathrm{Zn}_{2} \mathrm{H}_{4}$-STPPA and $\left[\mathrm{Co}_{2}\left(\mathrm{H}_{4}-\mathrm{MTPPA}\right)\right] \cdot 3 \mathrm{NMP} \cdot \mathrm{H}_{2} \mathrm{O}(\mathbf{1})$ are isostructural with different bond lengths and angles. The persistence and conformational flexibility of the eight-membered chains with different metals in metal organophosphonate chemistry are significant, ${ }^{20,23,26}$ as it could be further used as a reliable secondary building unit 


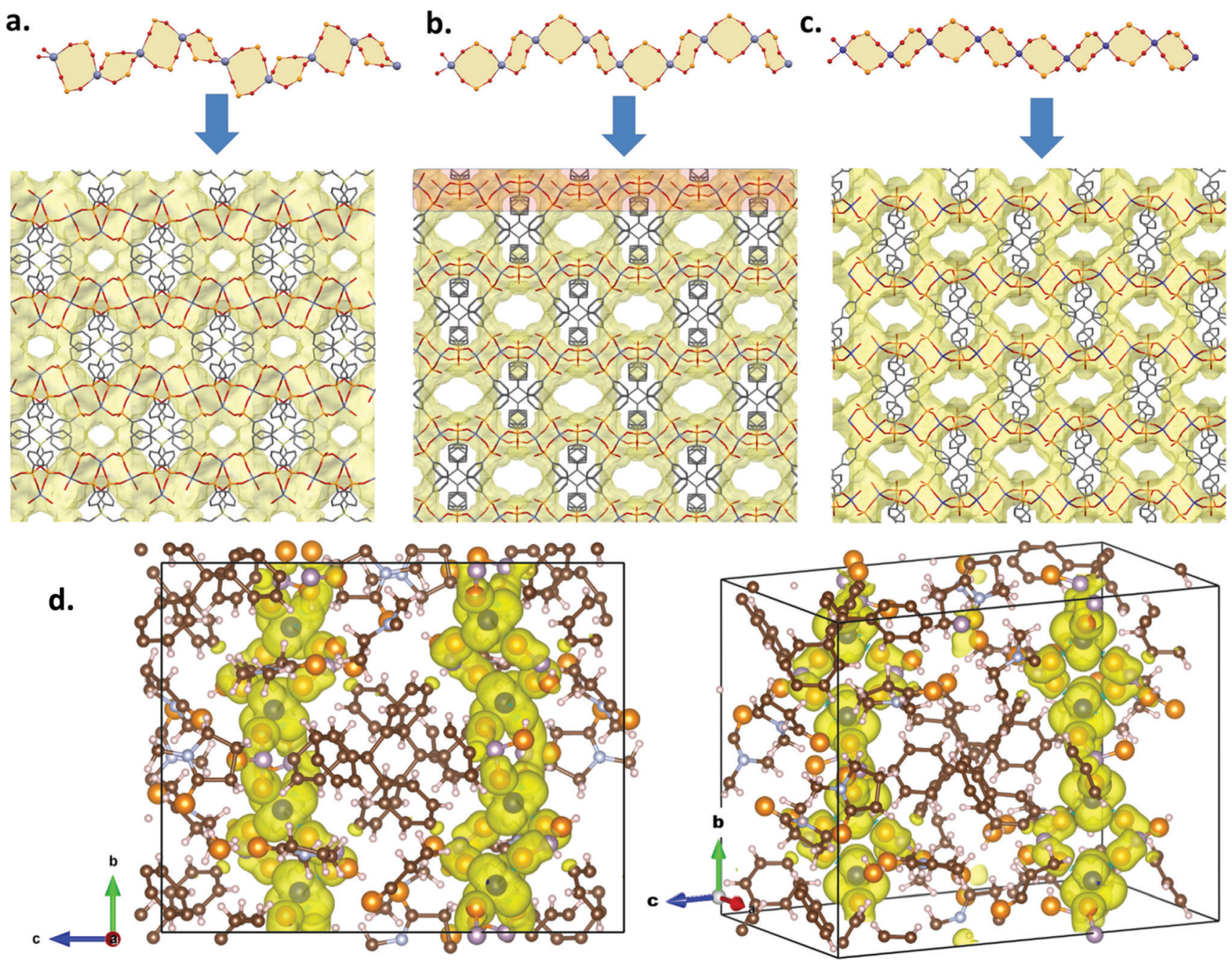

Fig. 1 The conformations of 1D IBUs composed of corner shared (a) $\mathrm{Zn}_{2} \mathrm{P}_{2} \mathrm{O}_{4}$ (in $\mathrm{Zn}_{2} \mathrm{H}_{4}$-STPPA) adapted from ref. 19; (b) $\mathrm{Zn}_{2} \mathrm{P}_{2} \mathrm{O}_{4}$ (in $\mathrm{Zn}_{2} \mathrm{H}_{4}-\mathrm{MTPPA}$ ) adapted from ref. 19; (c) $\mathrm{CO}_{2} \mathrm{P}_{2} \mathrm{O}_{4}$ in 1.3NMP. $\mathrm{H}_{2} \mathrm{O}$, and the perspective view of the three-dimensional porous framework of 1.3NMP. ${ }_{2} \mathrm{O}$. The change of conformational structure of the one-dimensional building block is significant in characterizing the porosity of the organophosphonate-MOF. The pore sizes are increasing from 564, 937 and $1034 \mathrm{~m}^{2} \mathrm{~g}^{-1}$ from left to right. The conformation of the 1D IBU is significant in determining the pore sizes. (d) Side and perspective view of the crystal cell for which DFT calculations have been carried out. The yellow cloud represents a typical isosurface of the charge density carrying a net spin which extends along the $b$ axis.

to construct predictable three-dimensional metal-organic frameworks using alternating tether lengths. The conformational flexibility of the chain structure observed in $\mathbf{1}$ could be further used to construct mechanically breathing metal-organic frameworks and isoreticular expansions with alternating tether lengths.

\section{Conflicts of interest}

There are no conflicts to declare.

\section{Notes and references}

1 O. M. Yaghi, M. O'Keeffe, N. W. Ockwig, H. K. Chae, M. Eddaoudi and J. Kim, Nature, 2003, 423, 705-714.

2 H. Furukawa, K. E. Cordova, M. O'Keeffe and O. M. Yaghi, Science, 2013, 341, 1230444.

3 S. M. Cohen, J. Am. Chem. Soc., 2017, 139, 2855-2863.

4 M. Taddei, R. J. Wakeham, A. Koutsianos, E. Andreoli and A. R. Barron, Angew. Chem., Int. Ed., 2018, 57, 11706-11710.
5 G. Ferey, Eur. J. Inorg. Chem., 2016, 4275-4277.

6 K. J. Gagnon, H. P. Perry and A. Clearfield, Chem. Rev., 2012, 112, 1034-1054.

7 M. Taddei, F. Costantino and R. Vivani, Eur. J. Inorg. Chem., 2016, 4300-4309.

8 G. Yücesan, Y. Zorlu, M. Stricker and J. Beckmann, Coord. Chem. Rev., 2018, 369, 105-122.

9 R. J. Motekaitis, I. Murase and A. E. Martell, Inorg. Chem., 1976, 15, 2303-2306.

10 T. K. Hurst, D. Wang, R. B. Thompson and C. A. Fierke, Biochim. Biophys. Acta, Proteins Proteomics, 2010, 1804, 393-403.

11 N. B. Padalwar and K. Vidyasagar, J. Solid State Chem., 2016, 243, 83-94.

12 R. Silbernagel, C. H. Martin and A. Clearfield, Inorg. Chem., 2016, 55, 1651-1656.

13 O. O. Ogunsolu, J. C. Wang and K. Hanson, ACS Appl. Mater. Interfaces, 2015, 7, 27730-27734.

14 T. L. Kinnibrugh, V. I. Bakhmutov and A. Clearfield, Cryst. Growth Des., 2014, 14, 4976-4984.

15 P. O. Adelani and T. E. Albrecht-Schmitt, Cryst. Growth Des., 2012, 12, 5800-5805.

16 N. L. Rosi, J. Eckert, M. Eddaoudi, D. T. Vodak, J. Kim, M. O’Keeffe and O. M. Yaghi, Science, 2003, 300, 1127-1129. 
17 N. Hermer, H. Reinsch, P. Mayer and N. Stock, CrystEngComm, 2016, 18, 8147-8150.

18 N. Hermer and N. Stock, Dalton Trans., 2015, 44, 3720-3723.

19 A. Schütrumpf, A. Bulut, N. Hermer, Y. Zorlu, E. Kirpi, N. Stock, A. O. Yazaydin, G. Yücesan and J. Beckmann, ChemistrySelect, 2017, 2, 3035-3038.

20 J. M. Taylor, A. H. Mahmoudkhani and G. K. H. Shimizu, Angew. Chem., Int. Ed., 2007, 46, 795-798.

21 A. Schütrumpf, A. Duthie, E. Lork, G. Yücesan and J. Beckmann, Z. Anorg. Allg. Chem., 2018, 644, 1134-1142.

22 T. Rhauderwiek, K. Wolkersdorfer, S. Oien-Odegaard, K. P. Lillerud, M. Wark and N. Stock, Chem. Commun., 2018, 54, 389-392.

23 B. Wang, T. Rhauderwiek, A. K. Inge, H. Xu, T. Yang, Z. Huang, N. Stock and X. Zou, Chem. - Eur. J., 2018, 27, 17429-17433.

24 T. Rhauderwiek, H. S. Zhao, P. Hirschle, M. Doblinger, B. Bueken, H. Reinsch, D. De Vos, S. Wuttke, U. Kolb and N. Stock, Chem. Sci., 2018, 9, 5467-5478.

25 A. Bulut, Y. Zorlu, E. Kirpi, A. Cetinkaya, M. Worle, J. Beckmann and G. Yücesan, Cryst. Growth Des., 2015, 15, 5665-5669.

26 C. Y. Gao, J. Ai, H. R. Tian, D. Wu and Z. M. Sun, Chem. Commun., 2017, 53, 1293-1296.

27 K. S. Walton and R. Q. Snurr, J. Am. Chem. Soc., 2007, 129, 8552-8556.

28 D. A. Gomez-Gualdron, P. Z. Moghadam, J. T. Hupp, O. K. Farha and R. Q. Snurr, J. Am. Chem. Soc., 2016, 138, 215-224.

29 A. Bulut, Y. Zorlu, M. Worle, A. Cetinkaya, H. Kurt, B. Tam, A. O. Yazaydin, J. Beckmann and G. Yücesan, ChemistrySelect, 2017, 2, 7050-7053.
30 J. M. Manriquez, G. T. Yee, R. S. Mclean, A. J. Epstein and J. S. Miller, Science, 1991, 252, 1415-1417.

31 T. Mallah, S. Thiebaut, M. Verdaguer and P. Veillet, Science, 1993, 262, 1554-1557.

32 S. Ferlay, T. Mallah, R. Ouahes, P. Veillet and M. Verdaguer, Nature, 1995, 378, 701-703.

33 G. M. Espallargas and E. Coronado, Chem. Soc. Rev., 2018, 47, 533-557.

34 H. Hyun, H. Wada, K. Bao, J. Gravier, Y. Yadav, M. Laramie, M. Henary, J. V. Frangioni and H. S. Choi, Angew. Chem., Int. Ed., 2014, 53, 10668-10672.

35 K. R. Bhushan, E. Tanaka and J. V. Frangioni, Angew. Chem., Int. Ed., 2007, 46, 7969-7971.

36 A. Zaheer, R. E. Lenkinski, A. Mahmood, A. G. Jones, L. C. Cantley and J. V. Frangioni, Nat. Biotechnol., 2001, 19, 1148-1154.

37 J. V. Frangioni, Curr. Opin. Chem. Biol., 2003, 7, 626-634.

38 F. N. Shi, J. C. Almeida, L. A. Helguero, M. H. V. Fernandes, J. C. Knowles and J. Rocha, Inorg. Chem., 2015, 54, 9929-9935.

39 G. Centi, F. Trifiro, J. R. Ebner and V. M. Franchetti, Chem. Rev., 1988, 88, 55-80.

40 G. Centi, Catal. Today, 1993, 16, 5-26.

41 X. M. Yu, J. R. Doroghazi, S. C. Janga, J. K. Zhang, B. Circello, B. M. Griffin, D. P. Labeda and W. W. Metcalf, Proc. Natl. Acad. Sci. U. S. A., 2013, 110, 20759-20764.

42 D. A. Born, E. C. Ulrich, K. S. Ju, S. C. Peck, W. A. van der Donk and C. L. Drennan, Science, 2017, 358, 1336-1338. 